have been possible were it not for the joint support of the City University of New York, Chiao-Tung University in Taiwan, and the Institute for History of Natural Sciences in Beijing.

What sets the history of mathematics apart from the history of science generally is that it is not an arcane history about past theories that have been discarded, forgotten as failed attempts to understand the workings of nature, but instead the history of mathematics is a living history. In the nineteenth century Weierstrass recommended that his students read the classics of the past, for such works might well contain ideas and methods that could still prove useful, even inspirational, to current mathematical research on the frontiers of the subject. It is for this reason that mathematicians, more than any other practitioners among the sciences, have a very real interest in their history-not just to remember the past, but to use it. For the tangible support and visibility that awards like the Whiteman Memorial Prize provide for the subject, historians of mathematics can truly be grateful, and at this moment in particular, none more than I. To the AMS Council and to the members of the selection committee, I want to express my sincere appreciation, and on behalf of historians of mathematics everywhere, my heartfelt thanks as well to Mrs. Sally Whiteman for establishing this outstanding memorial for her husband, Albert Leon Whiteman.

\section{About the Prize}

The Whiteman Prize is awarded every three years to recognize notable exposition and exceptional scholarship in the history of mathematics. The prize was established in 1998 using funds donated by Mrs. Sally Whiteman in memory of her husband, the late Albert Leon Whiteman. The prize carries a cash award of US\$5,000.

The Whiteman Prize is awarded by the AMS Council acting on the recommendation of a selection committee. For the 2012 prize, the members of the selection committee were Robin Hartshorne, Marjorie Senechal, and William C. Waterhouse. Previous recipients of the Whiteman Prize are Thomas Hawkins (2001), Harold M. Edwards (2005), and Jeremy J. Gray (2009).

- Elaine Kehoe

\title{
Award for Distinguished Public Service
}

WILLIAM MCCALLUM received the 2012 Award for Distinguished Public Service at the 118th Annual Meeting of the AMS in Boston in January 2012.

\section{Citation}

William McCallum is University Distinguished Professor and Head of the Mathematics Department at the University of Arizona. In recent years, McCallum has shown extraordinary energy in promoting improvement of mathematics education, and he has been almost ubiquitous in organizations devoted to mathematics education. He has served as chair of the Committee on Education of the AMS and as chair of CBMS. He is a member of the International Design Committee for the Klein Project, an effort of the International Commission on Mathematics Instruction and the International Mathematical Union to produce a set of narratives or "vignettes" about contemporary mathematics to educate and inspire today's high school teachers in the way that Felix Klein's lectures and books on "Elementary Mathematics from an Advanced Standpoint" did 100 years ago. He has also been

DOI: http://dx.doi.org/10.1090/noti822
Principal Investigator on a Mathematics and Science Partnership grant.

However, his most significant recent activities have also been the most distinctive. He is the founding Director of the Institute for Mathematics and Education (IME) at the University of Arizona and is currently director of its Advisory Committee. This Institute was founded explicitly on the principle that to deal effectively with issues of mathematics education requires communication and cooperation among teachers, mathematics education researchers, and mathematicians. In dozens of events over the past five years, many people from all three groups have met for mutually productive activities under the auspices of IME.

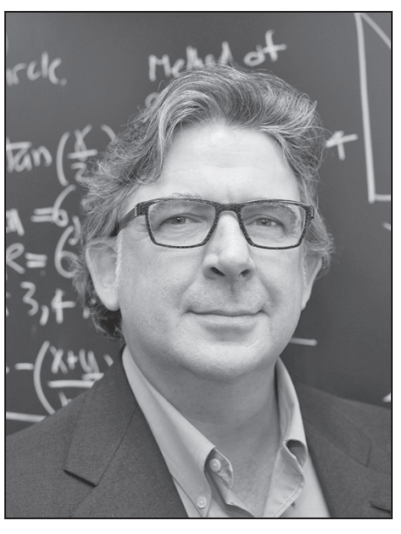

William McCallum
Mostrecently, hewas onemember of the three-person writing team selected by the Council of Chief State School Officers and the National Governors Association to orchestrate and execute the production of the Common Core State Math- 
ematics Standards. As such, he was the principal representative of the mathematics research community in the creation of the CCSS. The happy fact that so many mathematicians can read these standards with approval can be attributed in considerable part to his involvement.

\section{Biographical Sketch}

William McCallum was born in Sydney, Australia, and received his Ph.D. in mathematics from Harvard University in 1984 under the supervision of Barry Mazur. He has taught at the University of California, Berkeley, and the University of Arizona, where he is currently University Distinguished Professor. He is a founding member of the Harvard Calculus Consortium and has been a research fellow at the Mathematical Sciences Research Institute, the Institut des Haute Études Scientifiques, and the Institute for Advanced Studies. His honors include a Centennial Fellowship from the American Mathematical Society and a Director's Award for Distinguished Teaching Scholars from the National Science Foundation. In 2006 he founded the Institute for Mathematics and Education at the University of Arizona. His professional interests include arithmetical algebraic geometry and mathematics education.

\section{Response from William McCallum}

I am deeply honored to receive this award and accept it not only on my own behalf but also on behalf of the growing community of mathematicians who have chosen to dedicate their time and intellect to the scholarship of mathematics education. This community includes many previous recipients of this award and many others who deserve similar accolades. I am grateful for their leadership and inspiration. I am also grateful to the many mathematics educators and teachers with whom I have worked, both for their willingness to speak and for their willingness to listen as
I explored their communities. With the Institute for Mathematics and Education I have tried to build a home where mathematicians, educators, and teachers can meet, collaborate, and learn from each other, as I myself have learned from all three groups. I was fortunate to be at the right place at the right time when the Common Core State Standards initiative came along so that I was able to put my learning to good use. The Common Core is the best chance we have had in a long time to improve school mathematics education in this country; I invite my colleagues in the research community to join the effort to make it succeed.

\section{About the Award}

The Award for Distinguished Public Service is presented every two years to a research mathematician who has made a distinguished contribution to the mathematics profession during the preceding five years. The purpose of the award is to encourage and recognize those individuals who contribute their time to public service activities in support of mathematics. The award carries a cash prize of US\$4,000.

The Award for Distinguished Public Service is made by the AMS Council acting on the recommendation of the selection committee. For the 2012 award, the members of the selection committee were Richard A. Askey, C. H. Clemens, Roger E. Howe, Richard A. Tapia, and Sylvia M. Wiegand.

Previous recipients of the award are Kenneth M. Hoffman (1990), Harvey B. Keynes (1992), I. M. Singer (1993), D. J. Lewis (1995), Kenneth C. Millett (1998), Paul J. Sally Jr. (2000), Margaret H. Wright (2002), Richard Tapia (2004), Roger Howe (2006), Herbert Clemens (2008), and Carlos Castillo-Chavez (2010).

- Elaine Kehoe

\section{AMS-SIAM Birkhoff Prize}

BJORN ENGQUIST received the 2012 AMS-SIAM George David Birkhoff Prize in Applied Mathematics at the Joint Mathematics Meetings in Boston in January 2012.

\section{Citation}

The 2012 George David Birkhoff Prize in Applied Mathematics is awarded to Bjorn Engquist for his contributions to a wide range of powerful computational methods over more than three decades. DOI: http://dx.doi.org/10.1090/noti827
These include the numerical analysis of boundary conditions for wave propagation, which provided deep understanding about constructing accurate numerical schemes, efficient shock capturing schemes for nonlinear conservation laws which have found their way far beyond fluid mechanics into such disparate fields as image processing and materials, techniques for numerical homogenization, and methods for computing across multiple scales. His work blends mathematical analysis, modeling, and computation and has led to numerical tools with enormous impact across a broad 